\title{
NO better way to protect the heart during ischemia-reperfusion: to be in the right place at the right time
}

\author{
Charlotte Farah ${ }^{1,2}$ and Cyril Reboul ${ }^{1}$ * \\ 1 EA4278, LaPEC, Université d'Avignon, Avignon, France \\ 2 UMR-CNRS 9214, INSERM U1046, Université de Montpellier, Montpellier, France \\ *Correspondence: cyril.reboul@univ-avignon.fr \\ Edited by: \\ Michele Samaja, University of Milan, Italy \\ Reviewed by: \\ Pasquale Pagliaro, Università di Torino, Italy
}

Keywords: ischemia reperfusion, nitric oxide, S-nitrosylation, nitrite, pre-conditioning, post-conditioning

\section{INTRODUCTION}

Acute myocardial infarction (MI) is one of the leading causes of mortality worldwide. MI is the heart muscle irreversible death secondary to prolonged ischemia. Over the last few decades, medical progress in how and when to restore blood flow to the ischemic area have markedly improved patient survival. Although early heart reperfusion is acknowledged to be the most effective way to limit infarct size, post-ischemic reperfusion is associated with detrimental effects, such as myocardial stunning, ventricular arrhythmias, microvascular dysfunction, and cell death. The molecular mechanisms of these reperfusion injuries remain to be elucidated and their management is very challenging.

Among the various therapeutic molecular approaches proposed by experimental studies, nitric oxide (NO) role in protecting heart against MI and reperfusion injuries has been widely assessed and discussed (1-4). NO is a gasotransmitter that is abundantly produced in the cardiovascular system mainly by the NO synthase (NOS) enzymes system. Two isoforms, endothelial NOS (eNOS) and neuronal NOS (nNOS), are constitutively expressed in both myocardium and vessels, whereas inducible NOS (iNOS) is detected only in pathological conditions, such as inflammatory and/or oxidative stress. Both eNOS and nNOS are low-NO output $\mathrm{Ca}^{2+}$-dependent enzymes, while iNOS is a high-NO output $\mathrm{Ca}^{2+}$-independent enzyme. In physiological conditions, NOS form homodimers ("coupled" NOS) that catalyze NO production from L-arginine and $\mathrm{O}_{2}$ through electron transfer from NADPH on the reductase domain of one monomer to the oxidase domain of the second monomer. In pathological conditions, such as in the absence of the essential cofactor tetrahydrobiopterin $\left(\mathrm{BH}_{4}\right)$, eNOS can be "uncoupled" to produce $\mathrm{O}_{2}{ }^{-}$instead of NO.

In stress conditions, NO protects tissues through two distinct pathways. In the first one, NO activates the soluble guanylate cyclase (sGC) that initiates cyclic guanosine monophosphate (cGMP) production, leading to the activation of protein kinase $G$ (PKG). As $s G C$ is the major cell receptor for $\mathrm{NO}$ and the $\mathrm{NO} / \mathrm{sGC} / \mathrm{cGMP} / \mathrm{PKG}$ pathway plays a critical role in both myocardium excitationcontraction coupling and cardiovascular function regulation (5-8), NO cardioprotective role was first attributed to PKG activation (9-11). However, a second pathway in which proteins are directly modified by $\mathrm{NO}$ addition to sulfhydryl residues, a process known as S-nitrosylation (SNO), has recently emerged in the scientific literature. Although PKG activation pathway has been largely involved in NOmediated cardioprotection (11-13), SNO is now taking the front stage and is considered to be a key player in cardioprotection through (i) the transient modification of protein activity and/or (ii) their protection from irreversible oxidation (14-17). Indeed, Sun et al. (18) showed that reduced heart vulnerability to ischemia-reperfusion (IR) following acute ischemic preconditioning is mainly related to SNO signaling and not to PKG activation through the NO-SGC-cGMP pathway. Accordingly, we found that in exercise training-induced cardioprotection against IR injuries, protein SNO level, but not cGMP level, increased during early reperfusion (19). The same year, Methner et al. (20), using a Cre/loxP approach to selectively ablate type I PKG in cardiomyocytes, demonstrated that ischemic postconditioning reduced infarct size in these mice like in wild type controls. Moreover, they showed that the cardioprotective effect against IR injury of mitochondriatargeted S-nitrosothiol (MitoSNO), which allows NO and $S$-nitrosothiol accumulation in mitochondria, was comparable in mice that specifically lack PKG in cardiomyocytes and in controls. This indicates that MitoSNO cardioprotective effect is independent of PKG.

The current literature strongly supports NO implication in cardioprotection. However, the mechanism is still debated and whether increased $\mathrm{NO}$ availability during IR is cytoprotective remains to be demonstrated. Here, we discuss how NO might contribute to protect heart and particularly the importance of NO (i) localization, (ii) concentration, and (iii) time of availability during IR.

\section{RIGHT PLACE}

NO signaling depends on NOS cardiomyocyte subcellular localization $(8,21)$. Indeed, eNOS-catalyzed NO production occurs almost everywhere in the cell, thus leading to SNO of many targets (membrane and cytosolic proteins). On the other 
hand, nNOS colocalizes with SERCA and RyR and is associated with SNO mainly of reticulum sarcoplasmic proteins (16, 22). Although more than 1000 proteins are $S$-nitrosylated in hearts, recent findings suggest that cardiac mitochondrial proteins are key targets of NO-dependent cardioprotection. For instance, Sun et al. (23) reported that during ischemic preconditioning, caveolae-mediated transduction of eNOS/NO/SNO signaling to end-effector mitochondria leads to cardioprotection. Recently, Chouchani et al. (24) elegantly demonstrated that MitoSNO-induced heart protection could be explained by SNO of the ND3 subunit of mitochondrial complex I (on Cys39) to transiently lock it in a low-activity state, thus decreasing ROS production during early reperfusion. This SNO of the ND3 subunit was observed using an ischemic preconditioning experimental approach. Thus, through SNO, NO could directly protect mitochondrial proteins during IR. However, NO has also indirect effects. Indeed, Huang et al. (25) reported that SNO of G-proteincoupled receptor kinase 2 (GRK2) is the primary target of $\mathrm{NO}$ cardioprotective activity. Although GRK2 is a cytosolic protein that regulates the activity of Gprotein coupled receptors, the authors found that, during IR, GRK2 translocates to mitochondria and activates the cell death pathway. SNO-dependent inhibition of GRK2 could then have a protective effect, mainly by preserving mitochondrial integrity.

S-nitrosylation clearly has beneficial effects during IR when targeting specifically mitochondria; however, incorporation of a $\mathrm{NO}$ moiety $\left(\mathrm{NO}^{+}\right.$or $\left.\mathrm{NO}\right)$ to a sulfur atom can also be deleterious. Indeed, hypernitrosylation of RyR2 channels via the TNF- $\alpha /$ caspase 8 pathway increases $\mathrm{Ca}^{2+}$ leak from the sarcoplasmic reticulum (SR), thus contributing to cell death during IR (26). In this work, reduction of RyR2-SNO by using a caspase 8 inhibitor (Q-LETD-OPh) reduced infarct size in mice. On the other hand, RyR2 hyponitrosylation also promotes SR $\mathrm{Ca}^{2+}$ leak and thus might increase heart vulnerability to IR (27). Based on these results, Beigi et al. (28) demonstrated that dynamic SNO/denitrosylation reactions are essential for cardiovascular homeostasis.
Taken together, these data clearly show that SNO plays a key role in cardioprotection and also illustrate that this positive effect depends on the target and thus on the subcellular localization of NO synthesis. NO concentration could also be important and seems to be directly linked to the cellular redox state during IR (4). Indeed, although NO has undoubtedly a cardioprotective function, it could go over to the dark side, particularly if too much $\mathrm{NO}$ is produced or if it is available at the wrong moment.

\section{RIGHT CONCENTRATION}

In pro-oxidative conditions, such as during myocardial IR, $\mathrm{NO}$ can react with $\mathrm{O}_{2}{ }^{-}$to form peroxynitrite $\left(\mathrm{ONOO}^{-}\right)$, a cytotoxic molecule that is considered to be the main trigger of reperfusion injuries (29). Consequently, it is debated whether increasing NO bioavailability during IR has a cardioprotective effect (30). For instance, NOS overexpression, $\mathrm{BH}_{4}$ supplementation, or nitrite supplementation reduces heart sensitivity to IR (31-34). Also, numerous studies showed the cytoprotective function of iNOS during the specific late phase of preconditioning (35). But conversely, Csonka et al. (36) demonstrated that classical preconditioning induces cardioprotection by reducing NO harmful accumulation during early reperfusion. Consistently, the group of Zweier suggested that, in a pro-oxidative environment, transient limitation of NO synthesis via temporary S-gluthationylation-mediated NOS uncoupling might exert a cardioprotective effect by limiting $\mathrm{ONOO}^{-}$overproduction $(37,38)$. Similarly, we demonstrated that exercise-induced cardioprotection requires eNOS uncoupling during early reperfusion to limit excessive NO production and thus to reduce nitro-oxidative stress (19). If eNOS uncoupling during IR is corrected by $\mathrm{BH}_{4}$ supplementation, higher $\mathrm{ONOO}^{-}$production and increased infarct size are observed (19). Nonetheless, in this rat model of cardioprotection, reduced $\mathrm{NO}$ synthesis due to eNOS uncoupling during early reperfusion was counterbalanced by increased storage of $\mathrm{NO}$ metabolites (nitrite and $S$-nitrosothiols) in hearts of exercised rats (compared to sedentary controls). This allowed maintaining a high level of protein SNO, and thus of cardioprotection, during early reperfusion.
$\mathrm{NO}$ availability could mostly explain the discrepant findings concerning the effects of increasing or reducing $\mathrm{NO}$ synthesis during IR.

\section{RIGHT TIME}

The time of $\mathrm{NO}$ availability for SNO of key proteins during IR seems to be critical. Recently, Chouchani et al. (24) showed that SNO of mitochondrial complex I by MitoSNO can be observed only after ischemia and does not occur in normoxic hearts. The authors suggested that ischemia allows the exposure of Cys39 in the ND3 subunit of complex I for SNO. Considering that this mechanism is a key point of SNO-dependent cardioprotection, we can hypothesize that any strategy to make NO available during the ischemic period could contribute to protect the myocardium during IR. However, during ischemia, eNOS is not functional because it is monomerized, its activation by phosphorylation blunted (19) and its substrates (especially $\mathrm{O}_{2}$ ) are lacking. Therefore, $\mathrm{NO}$ availability in ischemic conditions is mainly dependent on NO metabolites (i.e., nitrite and $S$ nitrosothiols). Nitrite, a NO reservoir, is reduced to NO during ischemia by nitrite reductase (32) and $S$-nitrosothiols can decompose to liberate NO (39). Thus, oral treatment with nitrite (40) or acute nitrite administration before ischemia (41) increases NO metabolite storage, providing cardioprotection against IR. Moreover, nitrite therapy mediates cardioprotection by modulating mitochondrial function, leading to increased SNO of the ND3 subunit of the mitochondrial complex I (24). We (19) and others (42), showed that the beneficial effects of exercise on IR injuries are mainly mediated through the increase of the NO metabolite reserve before ischemia. In our work, such increase was associated with higher protein SNO level during early reperfusion. Finally, Calvert et al. (42) clearly demonstrated, using mice in which $\beta 3$ adrenergic receptor (which plays a key role in eNOS activation) was knocked out that inhibition of exercise-induced NO metabolite storage increase abolishes the cardioprotective effects of exercise against IR.

Altogether, these results indicate that ensuring NO availability during the 
ischemic period by increasing NO metabolites storage and improving SNO during early reperfusion are key steps for efficient cardioprotection.

\section{CONCLUSION}

$\mathrm{NO}$ is essential to limit the deleterious effects of post-ischemic reperfusion. Experimental studies indicate that NO exerts its cardioprotective effect against ischemia-reperfusion injuries not only directly through protein SNO but also indirectly through the NO/GCs/GMPc/PKG signaling pathway. Among the many cellular targets of NO, SNO of mitochondrial proteins during IR seems to play a key role. However, the efficiency of NOinduced cardioprotection depends on (i) its concentration, because NO can also generate nitro-oxidative stress (through the formation of $\mathrm{ONOO}^{-}$), (ii) its subcellular localization, and (iii) when it is available. Thus, improving NO metabolite (nitrites and $S$-nitrosothiols) storage before and during ischemia, to optimize NO availability and SNO during ischemia and early reperfusion, is an efficient strategy. Nevertheless, further studies are needed to better understand NO metabolism dynamics during IR in order to liberate the right amount of NO in the right place and at the right time.

\section{REFERENCES}

1. Schulz R, Kelm M, Heusch G. Nitric oxide in myocardial ischemia/reperfusion injury. Cardiovasc Res (2004) 61(3):402-13. doi:10.1016/j. cardiores.2003.09.019

2. Jones SP, Bolli R. The ubiquitous role of nitric oxide in cardioprotection. J Mol Cell Cardiol (2006) 40(1):16-23. doi:10.1016/j.yjmcc.2005.09.011

3. Pagliaro P, Moro F, Tullio F, Perrelli MG, Penna C. Cardioprotective pathways during reperfusion: focus on redox signaling and other modalities of cell signaling. Antioxid Redox Signal (2011) 14(5):833-50. doi:10.1089/ars.2010.3245

4. Tullio F, Angotti C, Perrelli MG, Penna C, Pagliaro P. Redox balance and cardioprotection. Basic Res Cardiol (2013) 108(6):392. doi:10.1007/s00395013-0392-7

5. Kojda G, Kottenberg K. Regulation of basal myocardial function by NO. Cardiovasc Res (1999) 41(3):514-23. doi:10.1016/S0008-6363(98) 00314-9

6. Hare JM. Nitric oxide and excitation-contraction coupling. J Mol Cell Cardiol (2003) 35(7):719-29. doi:10.1016/S0022-2828(03)00143-3

7. Massion PB, Feron O, Dessy C, Balligand JL. Nitric oxide and cardiac function: ten years after, and continuing. Circ Res (2003) 93(5):388-98. doi:10. 1161/01.RES.0000088351.58510.21
8. Carnicer R, Crabtree MJ, Sivakumaran V, Casadei B, Kass DA. Nitric oxide synthases in heart failure. Antioxid Redox Signal (2013) 18(9):1078-99. doi:10.1089/ars.2012.4824

9. Costa AD, Garlid KD, West IC, Lincoln TM, Downey JM, Cohen MV, et al. Protein kinase $\mathrm{G}$ transmits the cardioprotective signal from cytosol to mitochondria. Circ Res (2005) 97(4):329-36. doi:10.1161/01.RES.0000178451. $08719.5 \mathrm{~b}$

10. Agulló L, Garcia-Dorado D, Escalona N, RuizMeana $M$, Mirabet $M$, Inserte $J$, et al. Membrane association of nitric oxide-sensitive guanylyl cyclase in cardiomyocytes. Cardiovasc Res (2005) 68(1):65-74. doi:10.1016/j.cardiores.2005. 05.021

11. Penna C, Cappello S, Mancardi D, Raimondo S, Rastaldo R, Gattullo D, et al. Post-conditioning reduces infarct size in the isolated rat heart: role of coronary flow and pressure and the nitric oxide/cGMP pathway. Basic Res Cardiol (2006) 101(2):168-79. doi:10.1007/s00395-0050543-6

12. Inserte J, Barba I, Poncelas-Nozal M, Hernando V, Agulló L, Ruiz-Meana M, et al. cGMP/PKG pathway mediates myocardial postconditioning protection in rat hearts by delaying normalization of intracellular acidosis during reperfusion. J Mol Cell Cardiol (2011) 50(5):903-9. doi:10.1016/j.yjmcc. 2011.02.013

13. Inserte J, Hernando V, Vilardosa Ú, Abad E, Poncelas-Nozal M, Garcia-Dorado D. Activation of cGMP/protein kinase $G$ pathway in postconditioned myocardium depends on reduced oxidative stress and preserved endothelial nitric oxide synthase coupling. J Am Heart Assoc (2013) 2(1):e005975. doi:10.1161/JAHA.112. 005975

14. Cohen MV, Yang XM, Liu Y, Solenkova NV, Downey JM. Cardioprotective PKG-Independent NO Signaling at Reperfusion. Am J Physiol Heart Circ Physiol (2010) 299(6):H2028-36. doi:10. 1152/ajpheart.00527.2010

15. Sun J, Murphy E. Protein S-nitrosylation and cardioprotection. Circ Res (2010) 106(2):285-96. doi:10.1161/CIRCRESAHA.109.209452

16. Murphy E, Kohr M, Sun J, Nguyen T, Steenbergen C. S-Nitrosylation: a radical way to protect the heart. J Mol Cell Cardiol (2012) 52(3):568-77. doi:10.1016/j.yjmcc.2011.08.021

17. Tong G, Aponte AM, Kohr MJ, Steenbergen C, Murphy E, Sun J. Postconditioning leads to an increase in protein S-nitrosylation. Am J Physiol Heart Circ Physiol (2014) 306(6):H825-32. doi:10.1152/ajpheart.00660.2013

18. Sun J, Aponte AM, Kohr MJ, Tong G, Steenbergen C, Murphy E. Essential role of nitric oxide in acute ischemic preconditioning: S-Nitros(yl)ation versus sGC/cGMP/PKG signaling? Free Radic Biol Med (2013) 54:105-12. doi:10.1016/j.freeradbiomed. 2012.09.005

19. Farah C, Kleindienst A, Bolea G, Meyer G, Gayrard S, Geny B, et al. Exercise-induced cardioprotection: a role for eNOS uncoupling and NO metabolites. Basic Res Cardiol (2013) 108(6):389. doi:10.1007/ s00395-013-0389-2

20. Methner C, Lukowski R, Grube K, Loga F, Smith RA, Murphy MP, et al. Protection through postconditioning or a mitochondria-targeted Snitrosothiol is unaffected by cardiomyocyteselective ablation of protein kinase G. Basic Res Cardiol (2013) 108(2):337. doi:10.1007/s00395013-0337-1

21. Zhang YH, Casadei B. Sub-cellular targeting of constitutive NOS in health and disease. J Mol Cell Cardiol (2012) 52(2):341-50. doi:10.1016/j.yjmcc. 2011.09 .006

22. Sun J, Steenbergen C, Murphy E. S-nitrosylation: NO-related redox signaling to protect against oxidative stress. Antioxid Redox Signal (2006) 8(910):1693-705. doi:10.1089/ars.2006.8.1693

23. Sun J, Kohr MJ, Nguyen T, Aponte AM, Connelly PS, Esfahani SG, et al. Disruption of caveolae blocks ischemic preconditioning-mediated Snitrosylation of mitochondrial proteins. Antioxid Redox Signal (2012) 16(1):45-56. doi:10.1089/ars. 2010.3844

24. Chouchani ET, Methner C, Nadtochiy SM, Logan A, Pell VR, Ding S, et al. Cardioprotection by Snitrosation of a cysteine switch on mitochondrial complex I. Nat Med (2013) 19(6):753-9. doi:10.1038/nm.3212

25. Huang ZM, Gao E, Fonseca FV, Hayashi $H$, Shang X, Hoffman NE, et al. Convergence of G protein-coupled receptor and S-nitrosylation signaling determines the outcome to cardiac ischemic injury. Sci Signal (2013) 6(299):ra95. doi:10.1126/ scisignal.2004225

26. Fauconnier J, Meli AC, Thireau J, Roberge S, Shan J, Sassi Y, et al. Ryanodine receptor leak mediated by caspase- 8 activation leads to left ventricular injury after myocardial ischemia-reperfusion. Proc Natl Acad Sci U S A (2011) 108(32):13258-63. doi:10.1073/pnas. 1100286108

27. Gonzalez DR, Beigi F, Treuer AV, Hare JM. Deficient ryanodine receptor S-nitrosylation increases sarcoplasmic reticulum calcium leak and arrhythmogenesis in cardiomyocytes. Proc Natl Acad Sci U S A (2007) 104(51):20612-7. doi:10. 1073/pnas.0706796104

28. Beigi F, Gonzalez DR, Minhas KM, Sun QA, Foster MW, Khan SA, et al. Dynamic denitrosylation via S-nitrosoglutathione reductase regulates cardiovascular function. Proc Natl Acad Sci U S A (2012) 109(11):4314-9. doi:10.1073/pnas. 1113319109

29. Pacher P, Beckman JS, Liaudet L. Nitric oxide and peroxynitrite in health and disease. Physiol Rev (2007) 87(1):315-424. doi:10.1152/physrev.00029. 2006

30. Flögel U, Decking UK, Gödecke A, Schrader J. Contribution of NO to ischemia-reperfusion injury in the saline-perfused heart: a study in endothelial NO synthase knockout mice. J Mol Cell Cardiol (1999) 31(4):827-36. doi:10.1006/jmcc.1998.0921

31. Brunner F, Maier R, Andrew P, Wölkart G, Zechner R, Mayer B. Attenuation of myocardial ischemia/reperfusion injury in mice with myocytespecific overexpression of endothelial nitric oxide synthase. Cardiovasc Res (2003) 57(1):55-62. doi: 10.1016/S0008-6363(02)00649-1

32. Elrod JW, Calvert JW, Gundewar S, Bryan NS, Lefer DJ. Nitric oxide promotes distant organ protection: evidence for an endocrine role of nitric oxide. Proc Natl Acad Sci U S A (2008) 105(32):11430-5. doi:10.1073/pnas.0800700105 
33. Dumitrescu C, Biondi R, Xia Y, Cardounel AJ, Druhan LJ, Ambrosio G, et al. Myocardial ischemia results in tetrahydrobiopterin (BH4) oxidation with impaired endothelial function ameliorated by BH4. Proc Natl Acad Sci U S A (2007) 104(38):15081-6. doi:10.1073/pnas.0702986104

34. Bhushan S, Kondo K, Polhemus DJ, Otsuka $\mathrm{H}$, Nicholson CK, Tao YX, et al. Nitrite therapy improves left ventricular function during heart failure via restoration of nitric oxidemediated cytoprotective signaling. Circ Res (2014) 114(8):1281-91. doi:10.1161/CIRCRESAHA.114. 301475

35. Bolli R. Cardioprotective function of inducible nitric oxide synthase and role of nitric oxide in myocardial ischemia and preconditioning: an overview of a decade of research. J Mol Cell Cardiol (2001) 33(11):1897-918. doi:10.1006/jmcc.2001. 1462

36. Csonka C, Szilvássy Z, Fülöp F, Páli T, Blasig IE, Tosaki A, et al. Classic preconditioning decreases the harmful accumulation of nitric oxide during ischemia and reperfusion in rat hearts. Circulation (1999) 100(22):2260-6. doi:10.1161/01.CIR. 100.22.2260

37. Chen CA, Wang TY, Varadharaj S, Reyes LA, Hemann C, Talukder MA, et al.
S-glutathionylation uncouples enos and regulates its cellular and vascular function. Nature (2010) 468(7327):1115-8. doi:10.1038/nature09599

38. Zweier JL, Chen CA, Druhan LJ. Sglutathionylation reshapes our understanding of endothelial nitric oxide synthase uncoupling and nitric oxide/reactive oxygen speciesmediated signaling. Antioxid Redox Signal (2011) 14(10):1769-75. doi:10.1089/ars.2011.3904

39. Singh RJ, Hogg N, Joseph J, Kalyanaraman B. Mechanism of nitric oxide release from S-nitrosothiols. J Biol Chem (1996) 271(31):18596-603. doi:10.1074/jbc.271.31.18596

40. Bryan NS, Calvert JW, Elrod JW, Gundewar S, Ji SY, Lefer DJ. Dietary nitrite supplementation protects against myocardial ischemia-reperfusion injury. Proc Natl Acad Sci U S A (2007) 104(48):19144-9. doi:10.1073/pnas.0706579104

41. Webb A, Bond R, McLean P, Uppal R, Benjamin $\mathrm{N}$, Ahluwalia A. Reduction of nitrite to nitric oxide during ischemia protects against myocardial ischemia-reperfusion damage. Proc Natl Acad Sci U S A (2004) 101(37):13683-8. doi:10.1073/pnas. 0402927101

42. Calvert JW, Condit ME, Aragón JP, Nicholson CK, Moody BF, Hood RL, et al. Exercise protects against myocardial ischemia-reperfusion injury via stimulation of $\beta(3)$-adrenergic receptors and increased nitric oxide signaling: role of nitrite and nitrosothiols. Circ Res (2011) 108(12):1448-58. doi:10.1161/CIRCRESAHA.111.241117

Conflict of Interest Statement: The authors declare that the research was conducted in the absence of any commercial or financial relationships that could be construed as a potential conflict of interest.

Received: 05 January 2015; accepted: 26 January 2015; published online: 06 February 2015.

Citation: Farah C and Reboul C (2015) NO better way to protect the heart during ischemia-reperfusion: to be in the right place at the right time. Front. Pediatr. 3:6. doi: 10.3389/fped.2015.00006

This article was submitted to Pediatric Cardiology, a section of the journal Frontiers in Pediatrics.

Copyright (c) 2015 Farah and Reboul. This is an openaccess article distributed under the terms of the Creative Commons Attribution License (CC BY). The use, distribution or reproduction in other forums is permitted, provided the original author(s) or licensor are credited and that the original publication in this journal is cited, in accordance with accepted academic practice. No use, distribution or reproduction is permitted which does not comply with these terms. 